\title{
Fluoride Emission by an Aluminum Industry
}

\author{
Fabricio Narciso Olivati, Jaime Aparecido Cury* \\ Piracicaba Dental School, UNICAMP, Piracicaba, SP, Brazil \\ Email: jcury@unicamp.br
}

\begin{abstract}
The fluoride emission by an aluminum industry was estimated by the fluoride concentration in eucalyptus leaves (Eucalyptus grandis x Eucalyptus urophylla) located at distances of up to $1,700 \mathrm{~m}$ from the industry in Alumínio, SP, and Capão Bonito, SP, $150 \mathrm{~km}$ from the factory. The fluoride concentration in the aqueous extract of leaves of six trees was determined by specific ion electrode. The average concentrations $(\mathrm{mg} \mathrm{F} / \mathrm{kg}$ ) found in Alumínio were up to 100 times higher than those of Capão Bonito. It is concluded that there is environmental pollution by fluoride in the Alumínio city.
\end{abstract}

Keywords: fluorine, environmental pollution, aluminum, eucalyptus.

\section{Introduction}

Fluoride has been used for the dental caries control with safety for the people, and there isn't report that your use may be negative to the environment[2]. However, the fluoride is considered an environmental pollutant due to some industrial activities, as in the fertilizers and aluminum productions [4].

In fertilizers production, the fluoride pollution source is in the raw material. Phosphate minerals extracted from nature are treated with sulfuric acid, generating fluoride vapors that are emitted into the environment. These vapors affect every ecosystem and some native or planted plants around the factories can be used as biological markers of this pollution. Thus, through the chapeú-do-sol (Terminalia catappa) leaves, it was possible to prove that in 10 years, there isn't reduction in fluoride emissions by Cubatão fertilizer plants, in São Paulo, Brazil[1].

In aluminum production the fluoride pollution doesn't come from the raw material. Aluminum is produced from cryolite, a mineral that, unlike the phosphate rocks doesn't contain fluoride. Fluorine is used in the electrolytic process to produce aluminum in metallic form when the emission of fluorinecontaining vapors occurs. These vapors are incorporated into native or planted vegetables around the industry. Alumínio city, located in the São Paulo State, site of the largest aluminum industry in Brazil and the objective of this research was to evaluate the occurrence of fluoride emission by this industrial activity, using eucalyptus leaves as biomarker, for to be a specie cultivated throughout the region.

\section{Material and Methods}

\subsection{Sampling}

The samples were composed of Eucalyptus grandis x Eucalyptus urophylla leaves, hybrid specie popularly called eucalyptus, which due to its silvicultural characteristics has the purpose of supplying the pulp and paper industry. The trees were located at different distances from the aluminum industry $(250$ a $1700 \mathrm{~m})$, in urban area of Alumínio city, SP, Brazil.

Eucalyptus was chosen as a biological marker in the research because your species are found in practically all the regions in the urban zone of the city, including as a physical barrier around the industry, making it a convenience sample for this study.

Five collection points were defined in Alumínio, headquarters of the industry and surrounded by areas reforested with eucalyptus. The collection points were not in a straight line and were selected by the number of clustered trees and by unrestricted access to them. As a control, a collection point was 
selected in Capão Bonito city, SP, distant $150 \mathrm{~km}$ of Alumínio, which has one of the largest areas planted with eucalyptus in the state and doesn't have fluoride pollution emission (Figure 1).

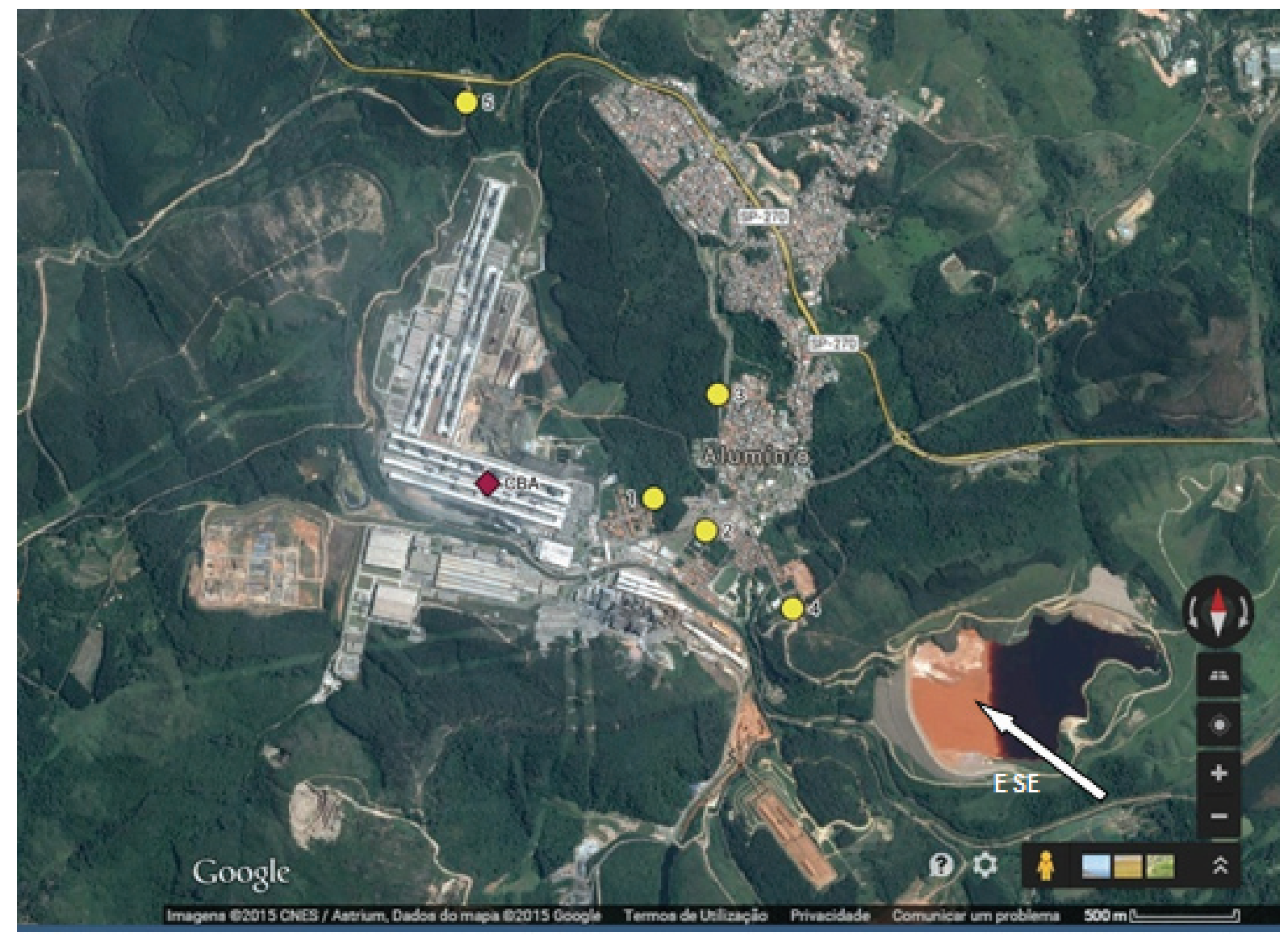

Figure 1. Satellite image of CBA aluminum industry in relation to the collection points of eucalyptus leaves samples, in Alumínio city, SP. Local of the fluoride gas emission source.

The samples were collected on trees with equivalent senescence, such as the size and location of branches and leaves. From the 6 points, 4 leaves of each organism, in their first branches, approximately $1.90 \mathrm{~m}$ from the ground, were collected from six trees $(\mathrm{n}=6)$. The leaf samples were collected in two distinct times: the first collection in March, 2014, representing the rainy period in the city and the second collection, held in August 2014, representing the dry season.

Immediately after each collection, the samples were wiped with damp cloth and packed in paper bags identified by codes according to the distances of the sources emitting pollution, measures per application of Global Positioning System - GPS.

\subsection{Fluoride Determination}

The fluoride concentration in the eucalyptus leaves was determined as previously described.[1] Briefly, the leaves were dehydrated in an oven at $90^{\circ} \mathrm{C}$ for $1 \mathrm{~h}$, milled and stored in a vacuum desiccator until analysis. Samples of 5 to $15 \mathrm{mg}( \pm 0.01 \mathrm{mg})$ were weighed in triplicate in plastic test tubes to which 1.0 $\mathrm{ml}$ of deionized and distilled water was added. After $1 \mathrm{~h}$ under stirring at $37{ }^{\circ} \mathrm{C}( \pm 0.1), 1.0 \mathrm{ml}$ of TISAB II (1 M acetate buffer $\mathrm{pH} 5.0$, containing $1 \mathrm{M} \mathrm{NaCl}$ and $0.4 \%$ CDTA) was added to the tubes. Fluoride extracted was determined with ion selective electrode Orion 96-09 BNWP (Thermo Fisher Scientific, Beverly, MA, USA) coupled to an ion analyzer Orion Star A211 (Thermo Fisher Scientific, Berverly, MA, USA) previously calibrated with fluoride standards ranging from 0.03 to $2.0 \mu \mathrm{g} F / \mathrm{ml}$ 
prepared in $50 \%(\mathrm{v} / \mathrm{v})$ TISAB II. The results were expressed in $\mu \mathrm{g} \mathrm{F} / \mathrm{g}$ for dry weight of the leaves, and the reproducibility of the analyzes was lower than $1 \%$.

\subsection{Statistical Analysis}

The data were tested for normality and homocessability by the Shapiro-Wilk method, but because they didn't meet the assumptions of the parametric methods, the time factor data were analyzed by the Wilcoxon test, and the local factor were analyzed by the Kruskal-Wallis test and compared by the Dunn method. Biostat software version 5.0 was used for the analysis, and the significance level was set at $5 \%$.

\section{Results}

The Table 1 shows that greater concentration of fluoride were found in the eucalyptus leaves located in Alumínio and the differences for the control city were statistically significant for most of the comparisons in the two collection times. In the first collection, the biggest difference was 30 times, but in the second it reached 100 times greater.

Table 1. Fluoride concentrations $(\mu \mathrm{g} F / \mathrm{g})$ in eucalyptus leaves according to the distance $(\mathrm{km})$ of aluminum industry located in Alumínio city, SP, Brazil, and of control city (Capão Bonito, SP, Brazil), and the collection times (mean $\pm \mathrm{SD}, \mathrm{n}=6$, range/minimum and maximum values).

\begin{tabular}{cccc}
\hline Cities/Collection & \multirow{2}{*}{$\begin{array}{c}\text { Distance of the } \\
\text { Points }\end{array}$} & \multicolumn{2}{c}{ Collection Time* } \\
\cline { 3 - 4 } Industry $(\mathbf{k m})$ & 0.25 & Mar/2014 & Aug/2014 \\
\hline Alumínio 1 & 0.35 & $133.2 \pm 42$. A $^{\mathrm{C}}(38.3-238.6)$ & $185.7 \pm 63.3^{\mathrm{A}}(69.3-458.7)$ \\
2 & 0.60 & $34.0 \pm 11.1^{\mathrm{A}, \mathrm{B}, \mathrm{C}}(22.1-53.9)$ & $24.3^{\mathrm{A}} \pm 6.5^{\mathrm{A}, \mathrm{B}}(8.3-48.1)$ \\
3 & 0.70 & $15.2 \pm 4.0^{\mathrm{A}, \mathrm{B}}(7.0-24.1)$ & $30.3 \pm 7.3^{\mathrm{A}, \mathrm{B}}(4.6-92.8)$ \\
4 & 1.70 & $118.9 \pm 32.0^{\mathrm{A}, \mathrm{C}}(18.0-297.8)$ & $162.5 \pm 42.7^{\mathrm{A}}(87,4-231.5)$ \\
5 & 150.0 & $3.8 \pm 0.3^{\mathrm{B}}(3.4-4.2)$ & $2.1 \pm 0.3^{\mathrm{B}}(1.6-2.4)$ \\
\hline
\end{tabular}

Means (data within columns) followed by different letters differed statistically ( $\mathrm{p}<0.05$, Kruskal - Wallis, Dunn).

*There was only significant difference between times of collection for point 1 in Alumínio and in Capão Bonito ( $p$ $<0.05$, Wilcoxon).

About the collection times difference significant was found only or the closest point of the factory in Alumínio and in Capão Bonito.

\section{Discussion}

The results (Table 1) clearly showed that there is fluoride emission in aluminum and the concentrations found are higher than 1 to $10 \mu \mathrm{g} / \mathrm{g}$, value considered as normal in regions not industrialized activity[3]. In contrast, the concentration found in eucalyptus leaves located in Capão Bonito, $150 \mathrm{~km}$ from the factory is within the range considered normal.

In addition, extremely high mean concentrations were found in the eucalyptus leaves located around the industry, in Alumínio city (Table 1). Concentrations between 25 and $80 \mu \mathrm{g} \mathrm{F} / \mathrm{g}$ may be considered toxic to vegetation[4] and in Alumínio only the eucalyptus analyzed in point 4 (first collection) and in point 3 (second collection) were found average concentrations below this value.

On the other hand, it was not found in Alumínio a linear relationship between the fluoride concentrations in eucalyptus leaves and the distance that the trees were located from the industry, contrasting with our expectation. This result can be explained by the fact that the distances chosen were not in a straight line and, so they were not in the same direction of the environmental winds of the region. Indeed, at the Alumínio collection point 5, located $1700 \mathrm{~m}$ from the industry, the mean fluoride concentrations of $118.9 \pm 32.0$ and $162.5 \pm 42.7$ (Table 1), in March and August respectively, were higher than closest to the industry and reflect the predominance of the direction of the local wind. To evaluate the effect of winds direction, it is necessary to design a specific research. 
Regarding the collection time factor studied (March and August 2014), higher concentration would be expected in August, winter time, due to differences in pollution dispersion, however, only a significant difference was found in the point located closer to the industry (Table 1). In the control of Capão Bonito, despite of the significant differences found for factor time, the fluoride concentrations found were consistent with the normal values considered in vegetations located in not industrialized cities. However, to evaluate the effect of seasons it is necessary further research collecting samples in all the periods of the year.

This pilot study provides support for a larger investigation to be conducted in Alumínio city because this fluoride emission certainly is not limited to the eucalyptus trees planted around the industry, but involves the region ecosystem. In addition, this emission may be putting at risk the aluminum industry workers, which can be confirmed by the urinary fluoride excretion by workers in samples collected before and after work, as determined by regulatory standard $\mathrm{n}^{\mathrm{O}} 7$, of the Program of Medical Control of Occupational Health, of Labor Ministry. [5]

In conclusion, fluoride environmental pollution produced by an aluminum factory in the city of Alumínio, São Paulo State, Brazil, is a fact and the possible impact of this pollution on workers' health, residents and animals in the industrial region should be evaluated.

\section{Reference}

1. Tagawa PT, Moruzzi DL, Cury JA. Fluoride concentration in the adjacent vegetation next to fertilizer industries of Cubatão, São Paulo State, Brazil. Cien Saude Colet, vol. 14, no. 6, pp. 2205-2208, 2009.

2. Tenuta LMA, Cury JA. Fluoride: Its role in dentistry. Braz Oral Res, vol. 24, no. Spec Iss 1, pp. 9-17, 2010.

3. Weinstein LH. Fluoride and plant life. Journal of Occupational Medicine,vol. 19, pp. 49-78, 1977.

4. Weinstein LH, Davison AW. Native plant species suitable as bioindicators and biomonitors for airborne fluoride. Environmental Pollution. vol. 125, no. 1: pp. 3-11, 2003.

5. Brazil. Labor and Employment Ministry. NR 7 - Occupational health medical control program. SSST Ordinance No. 24, of December 29, 1994. Brasília: D.O.U. of 12/30/94 - Section 1 - pg. 21278 and 21280. 